\title{
Popularity and customer preferences for over-the-counter Chinese medicines perceived by community pharmacists in Shanghai and Guangzhou: a questionnaire survey study
}

Shuai Ge, Tian-Tian He and HaO Hu*

\begin{abstract}
Background: This study interviewed community pharmacists in Shanghai and Guangzhou for their perception of the popular categories of over-the-counter (OTC) Chinese medicines and the factors affecting customer preferences for OTC Chinese medicines.

Methods: A cross-sectional survey was carried out in six main administrative districts in Guangzhou and eight main administrative districts in Shanghai, China. Descriptive statistical analysis was conducted in this study.

Results: OTC Chinese medicines contributed 21-50\% among all the pharmaceutical sales by the community pharmacies. The prevalent categories of OTC Chinese medicines were common cold medicines, respiratory system medicines, digestive system agents, gynecological medicines, health tonic medicines, and qing re (heat-clearing) and qu du (detoxifying) medicines. Customers were more concerned about medical factors of OTC Chinese medicines than business factors. Among the medical factors, the most important was drug safety, followed by efficacy, contraindications, indications, and side effects. Among the business factors, the most important were brand and price.
\end{abstract}

Conclusions: This study identified the top sales categories of OTC Chinese medicines in Shanghai and Guangzhou and the important factors such as drug safety, efficacy, period of validity, contraindications, and indications that are affecting the customer preferences for OTC Chinese medicines.

\section{Background}

Self-medication is becoming an increasingly important part of global healthcare systems where aging populations experience a higher prevalence of chronic medical conditions [1,2], including China where the pace of aging has been accelerating in the past decade [3]. Convenient self-medication with fewer adverse drug reactions is preferred [4]. Consequently, over-the-counter (OTC) medicines are gaining a significant presence in the pharmaceutical sector. For example, US sales of OTC Chinese medicines were about 1.7 billion US dollar in 2010 and there are approximately 100000 OTC products available in the US market [5,6]. These

\footnotetext{
* Correspondence: haohu@umac.mo

State Key Laboratory of Quality Research in Chinese Medicine, Institute of Chinese Medical Sciences, University of Macau, Macau, China
}

demographic and socioeconomic changes present opportunities for Chinese medicines in the OTC market.

Chinese medicines confer advantages in the selfmedication OTC market and increase drug accessibility for patients [7]. Specifically, OTC Chinese medicines are usually used without professional supervision [8], and their target mild diseases and chronic medical conditions do not need regular dose adjustments for long periods of time [9-11]. In addition, OTC Chinese medicines are more widely accepted than conventional Western medicines (WM) because of Chinese patients' beliefs and preferences for natural products and alternative medicines [12-14].

The factors that affect customer preferences for OTC Chinese medicines are under study to promote research and development (R\&D) of OTC Chinese medicines. As an important part of research on traditional Chinese 
medicine (TCM), R\&D of OTC Chinese medicines will contribute to the proposal of priority areas for future research and new drug innovations. Yu [15] proposed that medicinal products' quality and brand are the most critical factors for OTC Chinese medicine acceptance by customers. Toxic contaminants in OTC Chinese medicines are frequently discussed as a safety issue [16,17]. The appropriate dosages and schedules required to avoid common adverse reactions have also been the subject of research $[18,19]$. Moreover, researchers have begun to pay more attention to the cognitive preferences for OTC Chinese medicines [20]. Hon et al. [21] tested pharmacy students' attitudes toward OTC Chinese medicines, and discovered that pharmacy students' cognitive understanding of Chinese medicines significantly affected their attitudes toward OTC Chinese medicines. Chung et al. [22] investigated the use of OTC and prescription medicines across WM and TCM among urban Chinese patients and found that suggestions from healthcare professionals were highly relevant to patients' preferences for use of OTC products, regardless of whether WM or TCM was involved. However, related empirical studies remained limited and did not provide adequate knowledge of customer preferences for the development of OTC Chinese medicines.

Hospitals and community pharmacies were two main distribution channels for OTC Chinese medicines in China. Chinese medicines were widely used for treating cardiovascular and cerebrovascular diseases in hospitals (Additional file 1). This was followed by their use for cancer, and Chinese medicines were reported to cause less suffering and have significant efficacy in cancer treatment [23]. Chinese medicines were also widely used to treat respiratory diseases, musculoskeletal diseases, gynecological diseases, and urinary system diseases in hospitals. However, the most prevalent Chinese medicines used in hospitals were mostly Chinese medicine injections and belonged to the prescription medications [24]. OTC Chinese medicines did not have a significant presence in hospitals compared with prescription Chinese medicines [25,26].

Consequently, the most important market for OTC Chinese medicines in China is the community pharmacy $[27,28]$. However, no previous publications have focused on the popularity of OTC Chinese medicines in community pharmacies. The popular categories of OTC Chinese medicines in the community pharmacy market remained undefined and the factors affecting customer preferences for OTC Chinese medicines in community pharmacies were unknown.

This study aims to survey the popular categories of OTC Chinese medicines in community pharmacies in China and the factors affecting customer preferences for OTC Chinese medicines.

\section{Methods}

\section{Data collection}

This study used a paper-form questionnaire to collect first-hand data about OTC Chinese medicines in community pharmacies. The survey design was reviewed and approved by the Ethics Committee of the Research Committee at the University of Macau. Shanghai and Guangzhou were chosen as the target cities for this study because of their economic backgrounds, huge populations of TCM users, and citizens' acceptance toward TCM products as OTC Chinese medicines [29]. In more detail, the sales within the TCM industry in Guangdong province were 8.9 billion RBM, and accounted for $9.1 \%$ of the whole country sales in 2005 . The proportion of facilities with a TCM department among all 228 community health centers in Shanghai was $93.4 \%$ in 2006 . The two cities also have centralized leading TCM science and research institutes, including over 30 TCM research laboratories in Shanghai and 21 research institutes in Guangzhou [30-32]. The TCM culture in the two cities is also time-honored, for instance, there are more than four old-brand TCM enterprises established before the 19th century, indicating a long history of TCM use in Guangzhou [33].

Therefore, the information collected from community pharmacies in both cities could provide informative results about the popularity and customer preferences for OTC Chinese medicines in China.

The naive theory of popularity explained the belief that a product is desirable when it is popular [34,35]. The concept "popularity" was defined as a mixture of bestselling and prevalence, with the aim of indicating the market potential of OTC products. Because there was no reliable statistical information about the total number of community pharmacies in both cities, stratified sampling from different city districts was conducted to ensure that the study could collect information from community pharmacies located in different social and economic environments. All of the main administrative districts in Guangzhou were chosen, namely Tianhe, Yuexiu, Baiyun, Liwan, Huangpu, and Dongshan. The survey also covered all of the main administrative districts in Shanghai, including Huangpu, Luwan, Xuhui, Jingan, Putuo, Yangpu, Minhang, and Jinshan. The whole survey was conducted and completed in May 2013.

The pharmacist in charge of pharmaceutical services at each community pharmacy was targeted as the survey respondent. During visits to the community pharmacies, one researcher involved in the study as an investigator obtained informed consent in oral form from the respondents before the formal survey, following a standardized process: (1) introducing the researcher herself at first; (2) explaining research background and research objective in a structural way, with the cover page of questionnaire 
(Additional file 2); (3) clarifying the academic and anonymous nature of this survey; and (4) consulting the agreement of respondents. If there were any doubts in the survey, the investigator would spell out more specific information for the respondents in a word-by-word manner. The questionnaires were completed by the community pharmacists themselves without any intervention. All of the questionnaires were distributed directly to the respondents and collected on site in the same visit.

\section{Measurements}

A semi-structured questionnaire (Additional file 2) was used in this study. The questionnaire was composed of three parts. The first part solicited background information about the community pharmacy, specifically the year of establishment, number of employees, business area, geographic position, form of ownership, management model (chain drugstore or not), involvement in social medical security (yes or no), average number of daily customers, and provision of medical care services (yes or no).

The second part of the questionnaire solicited information about the popularity of OTC Chinese medicines. The respondents were asked to choose the sales proportions of four items: pharmaceutical sales/gross turnover; prescription medicine sales/pharmaceutical sales; OTC medicine sales/pharmaceutical sales; and OTC Chinese medicine sales/pharmaceutical sales. In addition, the respondents were asked to write down the five most popular categories of OTC Chinese medicines and the three best-selling products in each category.

The third part of the questionnaire investigated the factors affecting customer preferences for OTC Chinese medicines. The possible factors were divided into medical factors and business factors. The medical factors of OTC Chinese medicines referred to medicine safety, efficacy, dosage form, indications, contraindications, period of validity, and side effects. The business factors of OTC Chinese medicines referred to price, brand, production area, packaging, and label design, and whether the medicine was listed in the Catalogue of Drugs for Basic National Medical Insurance and Countermeasures of China (the Catalogue) [36]. The respondents were asked about the extent to which, in their experience, each factor influenced customer preferences for OTC Chinese medicines, measured on a 5 -point Likert scale $(1=$ not at all; 5 = very great). After the choices made by each respondent, the degree of influence was defined as the total choices related to each level (not at all, very great, or others) divided by the total number of respondents in percentages.

\section{Data analysis}

Preliminary analyses of the data collected in this study showed that there were no significant differences among the cities, geographic positions, forms of ownership, and business areas of the community pharmacies. Overall, the study aimed to provide a comprehensive exploration of OTC Chinese medicines in the community pharmacy market, rather than specific tests of community pharmacy factors. Therefore, the survey questionnaire data were analyzed through descriptive statistics. All the data for the background information of the community pharmacies, sales proportion items, and factors affecting customer preferences were analyzed through percentage distributions. The data for the popular categories of OTC Chinese medicines were analyzed by ordination methods through counting frequencies. The data for the popular products in each category were presented in word descriptions.

\section{Results}

\section{Background information for the community pharmacies evaluated}

A total of 108 community pharmacies in Guangzhou were visited, and 51 respondents completed the questionnaire. In Shanghai, 137 community pharmacies were visited, and 52 respondents completed the questionnaire. In total, 103 completed questionnaires were collected, with a response rate of $42 \%$, reflecting the difficulties in acquiring the cooperation of community pharmacists [37]. After deleting questionnaires with missing answers, 100 valid questionnaires were finalized for further analyses.

The year of establishment for the community pharmacies evaluated ranged from 1992 to 2012. On average, the community pharmacies had operated for 8 years. The number of employees ranged from 2 to 63 , with an average of 9.82 per community pharmacy.

As shown in Table 1, 42\% of the community pharmacies had a business area of $50-100 \mathrm{~m}^{2}$ and $38 \%$ of the community pharmacies had a business area of 100$150 \mathrm{~m}^{2}$. The majorities $(78 \%)$ of the community pharmacies evaluated were located in a residential community, $20 \%$ were in a business community, and the final $2 \%$ were in remote areas. The majority $(86 \%)$ of the community pharmacies were privately owned, $6 \%$ were stateowned, $4 \%$ belonged to foreign investors, and $4 \%$ were joint ventures between two ownership groups.

Sixty-four per cent of the community pharmacies were chain drugstores and 36\% were single drugstores. Fiftytwo per cent of the community pharmacies were involved in China's social medical security system. Through this system, Chinese citizens can defray some of the costs of medical expenses in the event of illness or injury, including expenditure on OTC Chinese medicines. However, only $20 \%$ of the community pharmacies offered medical care services. Thirty per cent of the community pharmacies served an average of 51-100 drug-purchasing customers daily and $18 \%$ of the community pharmacies served over 250 drug-purchasing customers each day. 
Table 1 Background information of the studied community pharmacies $(N=100)$

\begin{tabular}{|c|c|c|}
\hline Background & & Percentage \\
\hline \multirow[t]{3}{*}{ Geographic position } & Residential community & $78 \%$ \\
\hline & Business community & $20 \%$ \\
\hline & Remote areas & $2 \%$ \\
\hline \multirow[t]{4}{*}{ Form of ownership } & Private & $86 \%$ \\
\hline & State-owned & $6 \%$ \\
\hline & Foreign-owned & $4 \%$ \\
\hline & Joint venture & $4 \%$ \\
\hline \multirow[t]{2}{*}{ Management model } & Chain drugstore & $64 \%$ \\
\hline & Single drugstore & $36 \%$ \\
\hline \multirow{2}{*}{$\begin{array}{l}\text { Involved in social } \\
\text { medical security }\end{array}$} & Yes & $52 \%$ \\
\hline & No & $48 \%$ \\
\hline \multirow[t]{2}{*}{ Offer medical care services } & Yes & $20 \%$ \\
\hline & No & $80 \%$ \\
\hline \multirow[t]{5}{*}{ Business areas } & $0-50 m^{2}$ & $2 \%$ \\
\hline & $51-100 \mathrm{~m}^{2}$ & $42 \%$ \\
\hline & $101-150 \mathrm{~m}^{2}$ & $38 \%$ \\
\hline & $151-200 \mathrm{~m}^{2}$ & $6 \%$ \\
\hline & $>200 \mathrm{~m}^{2}$ & $12 \%$ \\
\hline \multirow{6}{*}{$\begin{array}{l}\text { Average number of } \\
\text { drug-purchasing } \\
\text { customers daily }\end{array}$} & $0-50$ & $14 \%$ \\
\hline & $51-100$ & $30 \%$ \\
\hline & $101-150$ & $16 \%$ \\
\hline & $151-200$ & $16 \%$ \\
\hline & $201-250$ & $6 \%$ \\
\hline & $>250$ & $18 \%$ \\
\hline
\end{tabular}

All community pharmacies sold both conventional medicines and Chinese medicines. OTC medicines contributed more toward sales income than prescription medicines. OTC Chinese medicines contributed 21-50\% of the income from pharmaceutical sales for the majority of the community pharmacies (Additional file 3).

\section{Popular categories of OTC Chinese medicines in the community pharmacies}

The six most popular categories of OTC Chinese medicines were cold medicines, respiratory system medicines, digestive system agents, gynecological medicines, health tonic medicines, and heat-clearing and detoxifying medicines (Table 2). The total frequency of these six categories in the data was approximately $81 \%$.

According to respondents' answers about the sales situation for OTC Chinese medicine products, the most popular products in each of the six most prevalent categories of OTC Chinese medicines were summarized in ordination (Table 3). These items comprised common products in OTC markets. For example, Xiaochaihu granules, made
Table 2 Categories of OTC Chinese medicine in the community pharmacies

\begin{tabular}{llll}
\hline Category no. & Categories & Frequency & Percentage \\
\hline 1 & Cold medicine & 91 & $18 \%$ \\
2 & Respiratory system medicine & 72 & $14 \%$ \\
3 & Digestive system agent & 67 & $13 \%$ \\
4 & Gynaecological medicine & 63 & $13 \%$ \\
5 & Health tonic medicine & 60 & $12 \%$ \\
6 & *Heat-clearing and & 54 & $11 \%$ \\
7 & detoxifying medicine & & \\
8 & ENT medicine & 28 & $6 \%$ \\
9 & Dermatology medicine & 24 & $5 \%$ \\
10 & Circulatory system agent & 17 & $3 \%$ \\
11 & Orthopaedics medicine & 15 & $3 \%$ \\
12 & Summer humidity agent & 8 & $2 \%$ \\
Total & Nervous system medicine & 1 & $0 \%$ \\
\hline
\end{tabular}

*Heat-clearing and detoxifying means Qingre Jiedu.

with the traditional Chinese medicines Bupleurum chinense and Scutellaria baicalensis, have obvious curative powers for flu and gastrointestinal dysfunction [38].

\section{Factors affecting customer preferences for OTC Chinese medicines}

The medical factors were the key factors affecting customer preferences for OTC Chinese medicines. Of the medical factors, medicine safety was the most important. The next most important factors were efficacy and period of validity. The factors of contraindications, indications, and side effects also had strong effects on customer decision-making. The dosage form did not have a strong effect on customer preferences (Figure 1).

The business factors, namely price, production area, brand, inclusion in the Catalogue, packaging, and label design, did not have such clear effects on customer preferences for OTC Chinese medicines. The medicine brand was a relatively more important factor, as were price and production area. Patients rarely considered packaging and label design, and did not consider whether their OTC Chinese medicine purchases were listed in the Catalogue, implying that their decision-making was not influenced by whether they would be reimbursed for their OTC Chinese medicines (Figure 2). As mentioned before, China's social medical insurance system was established to provide medical reimbursement and basic medical services to citizens, and the Catalogue is an important part of the system [39]. The Catalogue is able to balance the prices in the OTC market to some degree by adjusting the OTC medicines listed in the Catalogue [40]. However, similar to the consumer awareness of drug prices, the attention paid to the Catalogue was relatively low. 
Table 3 Popular products within the six most popular categories

\begin{tabular}{|c|c|}
\hline Categories & Popular products \\
\hline \multirow[t]{5}{*}{ Cold medicine } & 999 Ganmaoling granule \\
\hline & Xiaochaihu granule \\
\hline & Vitamin C Yinqiao tablet \\
\hline & Antiviral oral-liquid \\
\hline & Lianhua Qingwen capsule \\
\hline \multirow[t]{5}{*}{ Respiratory system medicine } & Milian Chuanbei Pipa paste \\
\hline & 999 Qiangli Pipa lu \\
\hline & Shedan Chuanbei liquid \\
\hline & Chuanbei Pipa paste \\
\hline & Juhong tanke liquid \\
\hline \multirow[t]{5}{*}{ Digestive system agent } & $\begin{array}{l}\text { Huoxiang Zhengqi liquid } \\
\text { (pill, capsule, liquid) }\end{array}$ \\
\hline & Jianwei Xiaoshi tablets \\
\hline & 999 Weitai granules \\
\hline & Stomach-recovering capsule \\
\hline & Health pill \\
\hline \multirow[t]{5}{*}{ Gynaecological medicine } & Fuyankang tablets \\
\hline & Gynecologic Qianjin tablets \\
\hline & Wuji Baifen Wan \\
\hline & Huahong tablets \\
\hline & Kanggongyan tablets \\
\hline \multirow[t]{5}{*}{ Health tonic medicine } & $\begin{array}{l}\text { Donkey-hide gelatin } \\
\text { (syrup, piece, particle, liquid) }\end{array}$ \\
\hline & Liuwei Dihuang pill \\
\hline & Renal Aid \\
\hline & Buzhong Yiqi pill \\
\hline & Anshen Bunao syrup \\
\hline \multirow[t]{5}{*}{ Heat-clearing and detoxifying medicine } & Banlangen granules \\
\hline & Niuhuang Jiedu tablets \\
\hline & Zhongsheng pill \\
\hline & Sanhuang tablets \\
\hline & Pudilan Xiaoyan tablets \\
\hline
\end{tabular}

\section{Discussion}

Based on the survey data, OTC Chinese medicines accounted for a high proportion of pharmaceutical sales in the community pharmacies evaluated, suggesting that OTC Chinese medicines have wide acceptance by Chinese customers and great potential in the self-medication market in China, especially through the distribution channel of community pharmacies.

The most common uses of Chinese medicines in hospitals are for the treatment of cardiovascular diseases, cancer, and other serious illnesses (see Additional file 1), which are obviously different from the uses of OTC Chinese medicine at community pharmacy. Thus, OTC
Chinese medicine producers could make use of their comparative advantages for common diseases and health maintenance areas, which have been regarded as one of the main strengths of Chinese medicines [41]. Thus, future $R \& D$ by OTC Chinese medicine producers could focus on the common disease areas targeted by Chinese medicines. For instance, Valerian extract capsules for the treatment of digestive system diseases and Jinggan capsules for the treatment of common colds were developed in 2011, and both focus on common disease areas [42]. Future $R \& D$ could also focus on the further development of existing OTC Chinese medicines and the improvement of their dose calculations to enlarge their market existence and increase customer acceptance.

According to the perceptions of community pharmacists, medicine safety and other medical factors were the key factors affecting customer preferences for OTC Chinese medicines. The community pharmacists surveyed thought that their customers were influenced more by medical factors than by business factors. Therefore, medical factors, comprising medicine safety, efficacy, period of validity, contraindications, indications, and side effects, were more influential factors for customers when choosing OTC Chinese medicines. Although most Chinese medicines are developed from natural products, safety problems have frequently been reported $[43,44]$. Over the past decade, a number of OTC Chinese medicines have been featured in the news after patients developed serious adverse effects arising from problems with the products, such as high heavy metal levels found in an aloe compound capsule and acute kidney injury caused by Han fang ji (Stephania tetrandra) [45]. Another medicine safety issue is improper use in self-medicating because of lack of knowledge [46-48]. Some OTC Chinese medicines might be subject to inadequate quality control and contain harmful additives or unlisted ingredients $[49,50]$. Furthermore, interactions between different products used simultaneously might cause serious problems [51,52].

Therefore, medicine safety should be the most important factor under consideration in drug use, especially the pharmacological, pharmacodynamics, and toxicological aspects, and adverse reactions of OTC Chinese medicines [53], as also identified in this study. In particular, rigorous guidelines and clinical trials specific to OTC Chinese medicines were required to be advanced and applied to ensure that clinical research is honest and reliable [54]. In addition, unsafe OTC Chinese medicines might arise from unprofessional practices by manufacturers [55]. Some of these problems could be controlled by the development of standard operating procedures for the industry, including good agricultural practice, good supply practice, and good manufacturing practice for implementation during OTC Chinese medicine production [56]. 


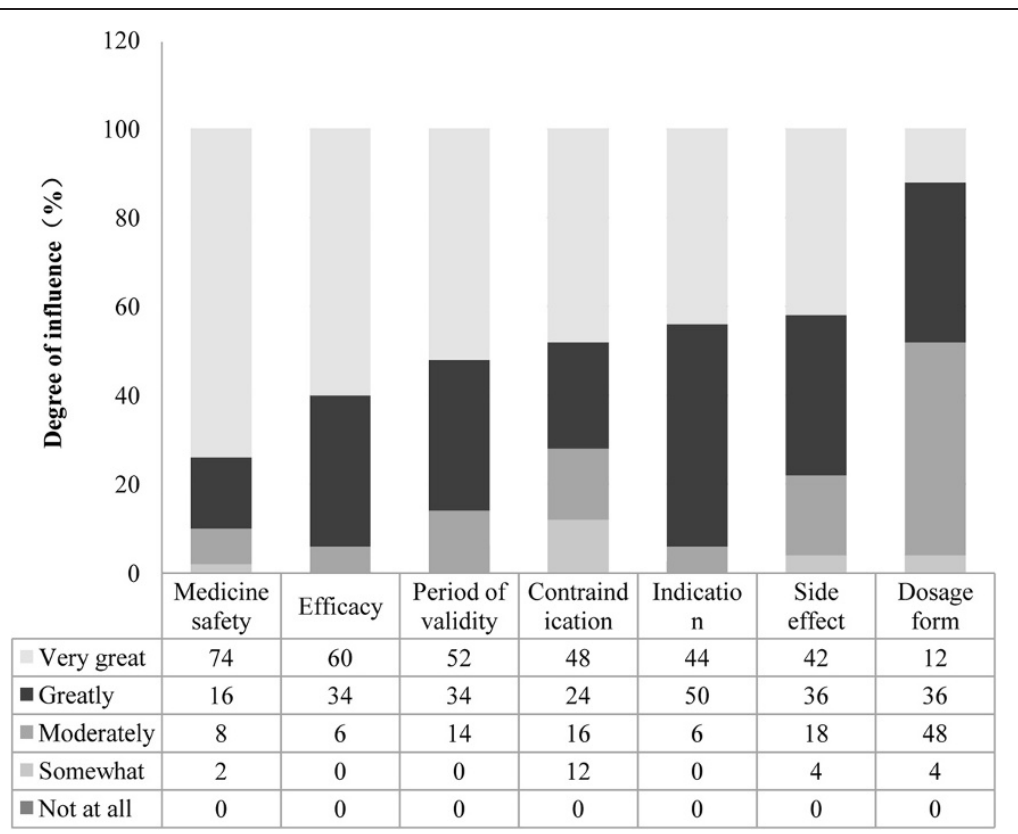

Figure 1 Medical factors affecting customer preference for OTC Chinese medicine.

Some factors did not significantly affect the customer preferences for OTC Chinese medicines, such as dosage form, packaging, and label design. Reimbursement and price were also not important. This might be because the medical security system in China was improved after the New Healthcare Reform, which included the addition of many more OTC Chinese medicines to the Catalogue [57]. Overall, 203 Chinese medicines were listed in the national essential drugs lists in 2012, occupying approximately one-third of the whole Catalogue [58]. Moreover, OTC Chinese medicines always have a competitive price advantage over most conventional WM $[59,60]$. Thus,

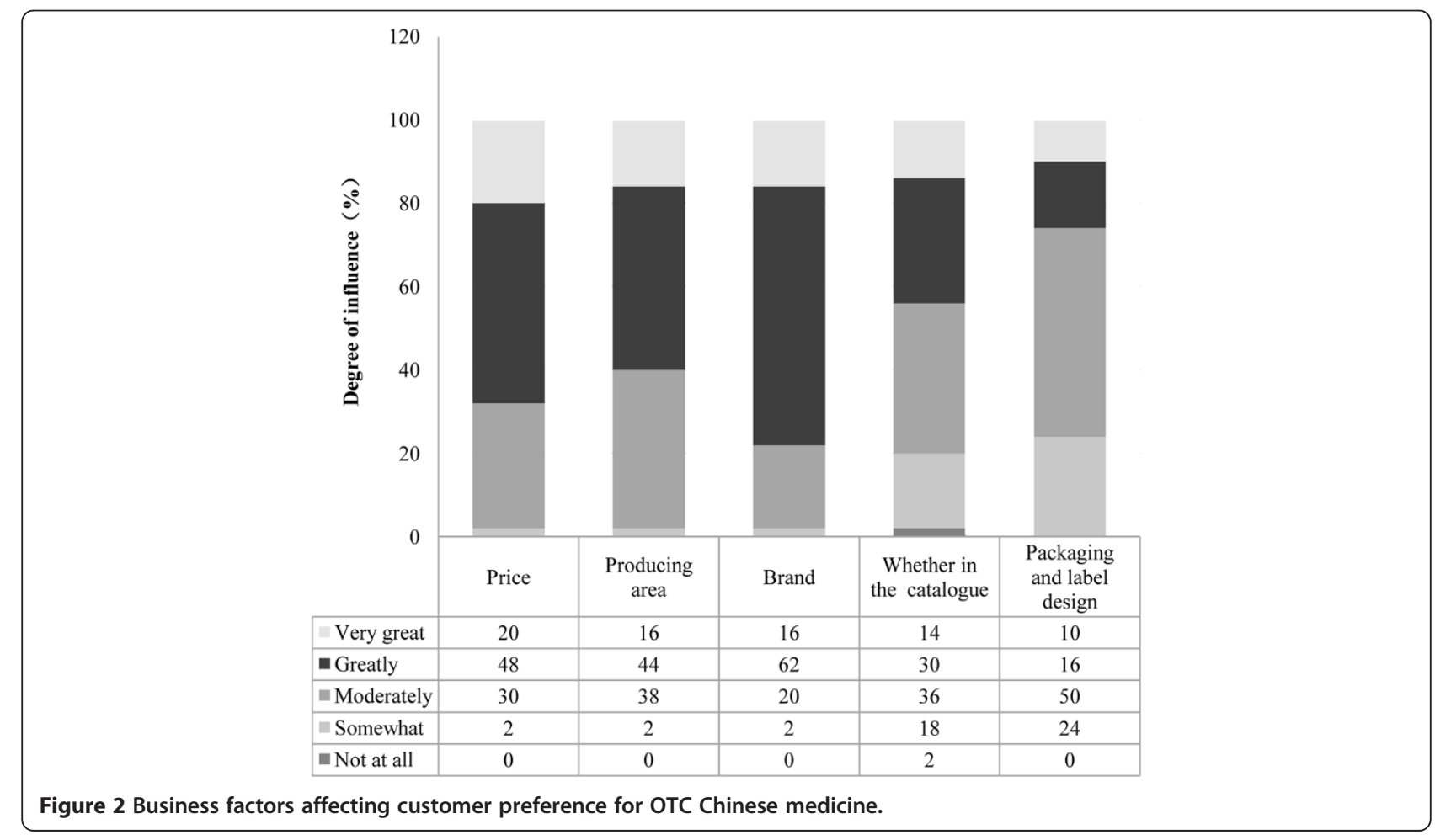


OTC Chinese medicines have many opportunities for growth in therapeutic areas, and it will be rewarding for producers to invest more money into $R \& D$ for OTC Chinese medicines.

Several study limitations should be addressed in future studies. First, the survey used for data collection was restricted to specific areas. Although Shanghai and Guangzhou could provide information about the main consumption of OTC Chinese medicines in China, the results may not accurately represent the situations in middle- and small-sized cities. Future studies covering more geographical areas would provide more complete information about OTC Chinese medicines in different economic and social contexts. Second, this study was based on the perceptions of community pharmacists rather than direct measurements of OTC Chinese medicine consumption. Future studies could be advanced through the creation of new methods to collect direct consumption data. Third, this study used an overview of the popular categories and products of OTC Chinese medicines. Further research could focus on specific categories. The treatment areas of cold medicines and digestive system agents, for example, contain various complex OTC Chinese medicines and require more detailed study.

\section{Conclusions}

This study identified the top sales categories of OTC Chinese medicines in Shanghai and Guangzhou and the important factors such as drug safety, efficacy, period of validity, contraindications, and indications that are affecting the customer preferences for OTC Chinese medicines.

\section{Additional files}

Additional file 1: Shares of Chinese medicines in hospital (2005-2011).

Additional file 2: Popularity and customer preference of OTC Chinese medicine questionnaire.

Additional file 3: Sales proportion in community pharmacies.

\section{Competing interests}

The authors declare that they have no competing interests.

\section{Authors' contributions}

SG and HH conceived and designed the study. SG conducted the fieldwork. $\mathrm{SG}, \mathrm{TTH}$ and $\mathrm{HH}$ performed the data analysis. TTH and $\mathrm{HH}$ wrote the manuscript. All authors read and approved the final manuscript.

\section{Acknowledgements}

This study was supported by a grant from the University of Macau (MYRG044 (Y1-L1)-ICMS12-HH). All authors also wish to acknowledge the encouragement and support of Professor Yi-Tao Wang for this study.

Received: 28 October 2013 Accepted: 12 September 2014

Published: 13 September 2014

\section{References}

1. Pandya RN, Jhaveri KS, Vyas FI, Patel VJ: Prevalence, pattern and perceptions of self-medication in medical students. Int J Basic Clin Pharmacol 2013, 2(3):275-280.

2. You JH, Wong FY, Chan FW, Wong EL, Yeoh EK: Public perception on the role of community pharmacists in self-medication and self-care in Hong Kong. BMC Clin Pharmacol 2011, 11(1):19.

3. Baeten S, Van Ourti T, Van Doorslaer E: Rising inequalities in income and health in China: who is left behind? J Health Econ 2013, 32(6):1214-1229.

4. Yuefeng $L$, Kegin $R$, Xiaowei $R$ : Use of and factors associated with self-treatment in China. BMC Public Health 2012, 12:995.

5. Bower AB, Grau SL, Taylor VA: Over-the-counter vs. prescription medications: are consumer perceptions of the consequences of drug instruction non-compliance different? Int J Consum Res 2012, 37(2):229-233.

6. Chung CH, Lau CH, Chan WK, You HS, Wong LY, Griffiths SM: Use of Chinese and western over-the-counter medications in Hong Kong. Chin Med 2010, 5:41.

7. Ryan M, Yule B: Switching drugs from prescription-only to over-thecounter availability: economic benefits in the United Kingdom. Health Policy 1990, 16(3):233-239.

8. Lynch N, Berry D: Differences in perceived risks and benefits of herbal, over-the-counter conventional, and prescribed conventional, medicines, and the implications of this for the safe and effective use of herbal products. Complement Ther Med 2007, 15:84-91.

9. Bradley C, Blenkinsopp A: Over the counter drugs: The future for self-medication. BMJ 1996, 312(7034):835-837.

10. Feng $Y$, Wu Z, Zhou $X$, Zhou Z, Fan W: Knowledge discovery in traditional Chinese medicine: state of the art and perspectives. Artif Intell Med 2006, 38(3):219-236.

11. Harmsworth K, Lewith GT: Attitudes to traditional Chinese medicine amongst Western trained doctors in the People's Republic of China. Soc Sci Med 2001, 52(1):149-153.

12. Furnham A, Vincent C, Wood R: The health beliefs and behaviors of three groups of complementary medicine and a general practice group of patients. J Altern Complement Med 1995, 1(4):347-359.

13. Chan MF, Mok E, Wong YS, Tong TF, Day MC, Tang CKY, Wong DHC: Attitudes of Hong Kong Chinese to traditional Chinese medicine and western medicine: survey and cluster analysis. Complement Ther Med 2003, 11(2):103-109.

14. Shahrokh LE, Lukaszuk JM, Prawitz AD: Elderly herbal supplement users less satisfied with medical care than nonusers. J Am Diet Assoc 2005, 105(7):1138-1140.

15. Yu WZ: The marketing innovation of the self-medication OTC drugs with reference to the reform of medical treatment. In The Proceedings of 2009 International Conference on Information Management, Innovation Management and Industrial Engineering, 26-27 December, 2009, Xi'an. IEEE: IEEE; 2009:81-87.

16. Chan K: Some aspects of toxic contaminants in herbal medicines. Chemosphere 2003, 52(9):1361-1371.

17. Saad B, Azaizeh H, Abu-Hijleh G, Said O: Safety of traditional Arab herbal medicine. Evid Based Complement Alternat Med 2006, 3(4):433-439.

18. Cheng JT: Drug therapy in Chinese traditional medicine. J Clin Pharmacol 2000, 40(5):445-450.

19. Wenzel RG, Sarvis CA, Krause ML: Over-the-counter drugs for acute migraine attacks: literature review and recommendations. Pharmacotherapy 2003, 23:494-505.

20. Chung VC, Ma PH, Lau CH, Wong SY, Yeoh EK, Griffiths SM: Views on traditional Chinese medicine amongst Chinese population: a systematic review of qualitative and quantitative studies. Health Expect 2012, May 31. doi:10.1111/j.1369-7625.2012.00794.x. [Epub ahead of print].

21. Hon EK, Lee K, Tse HM, Lam LN, Tam KC, Chu KM, Lee V, Lau C, Leung TF: A survey of attitudes to traditional Chinese medicine in Hong Kong pharmacy students. Complement Ther Med 2004, 12(1):51-56.

22. Chung VC, Ma PH, Tang TS, Lau CH, Kim JH, Griffiths SM: Do patients tell their clinicians they are using both prescribed and over the counter allopathic and traditional medicines? Eur J Integr Med 2011, 3(4):289-298.

23. Li X, Yang G, Li X, Zhang Y, Yang J, Chang J, Sun X, Zhou X, Guo Y, Xu Y, Liu J, Bensoussan A: Traditional Chinese medicine in cancer care: a review of controlled clinical studies published in Chinese. PLoS One 2013, 8(4):e60338.

24. Liao YH, Lin CC, Li TC, Lin JG: Utilization pattern of traditional Chinese medicine for liver cancer patients in Taiwan. BMC Complement Altern Med 2013, 12:146. 
25. Li GD, Wu XF: Feasibility and design about OTC pharmacies in hospitals. Guo Ji Yi Yao Wei Sheng Dao Bao 2004, 10(8):143-145.

26. Company MDC: Market research of clinical medication in hospitals of traditional Chinese medicine in 2004. Beijing: MDC Company; 2004.

27. Smith F: The extended role of the community pharmacist: implications for the primary health care team. J Soc Admin Pharm 1990, 7:101-110.

28. Chan TYK, Lee KKC, Critchley JAJH: The needs and sources of drug information among pharmacists in Hong Kong. J Clin Pharm Ther 1996, 21(5):325-330

29. Fang $Y$, Yang $S$, Zhou $S$, Jiang $M$, Liu J: Community pharmacy practice in China: past, present and future. Int J Clin Pharm 2013, 35(4):520-528.

30. People's Government of Guangdong Province: The Eleventh Five Year Development Plan of the Traditional Chinese Medicine in Guangdong. In [http://www.gd.gov.cn/govpub/fzgh/hygh/0200702070036.htm]

31. Shanghai Municipal Commission of Health and Family Planning: The Twelfth Five Year Development Plan of the Traditional Chinese Medicine in Shanghai. In [http://www.wsjsw.gov.cn/wsj/n429/n432/n1485/n1496/ u1ai80358.html]

32. Guangzhou Municipal Development Reform Commission: The Twelfth Five Year Development Plan of the Traditional Chinese Medicine in Guangzhou. In [http://www.gzplan.gov.cn/publicfiles/business/htmlfiles/ gzplan/qtwj/201402/2608403.html]

33. Chen XQ: Main lists of time-honored Chinese medicine companies in business after the Liberation. Zhongguo Yao Xue Za Zhi 1999, 34(9):632.

34. Cialdini RB: Influence. New York: HarperCollins e-books: New York Press; 2009.

35. Deval H, Mantel SP, Kardes FR, Posavac SS: How naïve theories drive opposing inferences from the same information. J Consum Res 2013, 39:1185-1201

36. Guan $X$, Liang $H$, Xue $Y$, Shi $L$ : An analysis of China's national essential medicines policy. J Public Health Policy 2011, 32(3):305-319.

37. Baruch $Y$ : Response rates in academic studies-a comparative analysis. Hum Relat 1999, 52:421-434.

38. Cao JJ: Study on pharmacodynamics of Xiao-chai-hu tablets. Zhongguo Lin Chuang Yao Li Xue Za Zhi 2010, 26(2):88-89.

39. China Food and Drug Administration: Notice about opinion of the establishment and implementation of National Essential Drugs System. In [http://www.sda.gov.cn/WS01/CL0611/40753.html]

40. Li BM: The developing trend of the OTC market and research of the main popular OTC brand products in China. Heilongjiang Yi Xue Za Zhi 2014, in press.

41. Cheung F: TCM: Made in China. Nature 2011, 480(7378):S82-S83.

42. Kim JH, Kwong EM, Chung VC, Lee JC, Wong T, Goggins WB: Acute adverse events from over-the-counter Chinese herbal medicines: a populationbased survey of Hong Kong Chinese. BMC Complement Altern Med 2013, 13:336.

43. Boullata JI, Nace AM: Safety issues with herbal medicine. Pharmacotherapy 2000, 20(3):257-269.

44. Luo H, Li Q, Flower A, Lewith G, Liu JP: Comparison of effectiveness and safety between granules and decoction of Chinese herbal medicine: a systematic review of randomized clinical trials. J Ethnopharmacol 2012, 140(3):555-567.

45. Jha V, Rathi M: Natural medicines causing acute kidney injury. Semin Nephrol 2008, 28(4):416-428.

46. Kelvin C: An overview on safety issues of interactions between traditional herbal medicines and pharmaceutical medicines. Boletín Latinoamericano y del Caribe de Plantas Medicinales y Aromáticas 2008, 7(6):312-331.

47. Raynor DK, Dickinson R, Knapp P, Long AF, Nicolson DJ: Buyer beware? Does the information provided with herbal products available over the counter enable safe use? BMC Med 2011, 9:94

48. Hughes L, Whittlesea C, Luscombe D: Patients' knowledge and perceptions of the side-effects of OTC medication. J Clin Pharm Ther 2002, 27(4):243-248

49. Tachjian A, Maria $V$, Jahangir A: Use of herbal products and potential interactions in patients with cardiovascular diseases. J Am Coll Cardiol 2010, 55(6):515-525.

50. Gratus C, Wilson S, Greenfield SM, Damery SL, Warmington SA, Grieve R, Steven NM, Routledge P: The use of herbal medicines by people with cancer. BMC Complement Altern Med 2009, 9:14.

51. Xu Q, Bauer R, Hendry BM, Fan TP, Zhao Z, Duez P, Simmonds MS, Witt CM, Lu A, Robinson N, Guo DA, Hylands PJ: The quest for modernisation of traditional Chinese medicine. BMC Complement Altern Med 2013, 13:132.
52. Mhatre SSS: Over-the-counter medication use and its impact on quality of life of the elderly. Value Health 2012, 15:A203.

53. Song PP, Gao JJ, Kokudo N, Tang W: Standardization of traditional Chinese medicine and evaluation of evidence from its clinical practice. Drug Discov Ther 2011, 5(6):261-265.

54. Shang HC, Li YP, Chen J, Zhang JH, Zhang BL: New trends for clinical research of traditional Chinese medicine in China. Chin Med J (Engl) 2008, 121(11):1050-1051.

55. Kim JH, Chung CHV, Lau CH, Goggins WB, Lau JT, Griffiths S: Adverse events and poisonings from over-the-counter Traditional Chinese Medicine: A population-based survey for improving consumer safety. In Research Fund for the Control of Infectious Diseases; 2012 [http://fhbgrants. netsoft.net/english/funded_list/funded_list_detail.php?id=1018\&no=331]

56. Fan TP, Deal G, Koo HL, Rees D, Sun H, Chen S, Dou JH, Makarov VG, Pozharitskaya ON, Shikov AN, Kim YS, Huang YT, Chang YS, Jia W, Dias A Wong VC, Chan K: Future development of global regulations of Chinese herbal products. J Ethnopharmacol 2012, 140(3):568-586.

57. Liu GG, Zhao Z, Cai R, Yamada T: Equity in health care access to: assessing the urban health insurance reform in China. Soc Sci Med 2002, 55(10):1779-1794.

58. Chung VC, Ma PH, Wang HH, Wang JJ, Hong LC, Wei X, Wong SY, Tang JL, Griffiths SM: Integrating traditional Chinese medicine services in community health centers: insights into utilization patterns in the Pearl River Region of China. Evid Based Complement Alternat Med 2013, 426360

59. Cai Y, Mao Z, Xu B, Wu B: Factors associated with traditional Chinese medicine utilization among urban community health centers in Hubei Province of China. Asia-Pacific. J Public Health 2013, published online before print, doi:10.1177/1010539513491415.

60. Cho JH, Lee TJ: The factors contributing to expenditures on over-thecounter drugs in South Korea. Value in Health Regional Issues 2013, 2(1):147-151.

doi:10.1186/1749-8546-9-22

Cite this article as: Ge et al:: Popularity and customer preferences for over-the-counter Chinese medicines perceived by community pharmacists in Shanghai and Guangzhou: a questionnaire survey study. Chinese Medicine 2014 9:22.

\section{Submit your next manuscript to BioMed Central and take full advantage of:}

- Convenient online submission

- Thorough peer review

- No space constraints or color figure charges

- Immediate publication on acceptance

- Inclusion in PubMed, CAS, Scopus and Google Scholar

- Research which is freely available for redistribution 